\title{
Effect of Bioenhancers on Amoxicillin bioavailability
}

\author{
Kalyani Barve*, Kushal Ruparel \\ SPP - School of Pharmacy and technology management, SVKM's NMIMS, Vile Parle (West), Mumbai -400056, India.
}

*Corresponding Author: E-mail: barve.kalyani@gmail.com; Tel.: +91-22-42332000; Fax: +91-22-26185422

Received: January 29, 2015; Revised: February 24, 2015; Published: March 31, 2015

\begin{abstract}
Amoxicillin, which inspite of being effective is losing its importance due to less bioavailability. Bioavailability could be enhanced by combining the antibiotics with bioenhancers like Piperine and Ginger resin. The present abstract deals with the use of piperine and ginger resin in increasing the bioavailability of amoxicillin using the insitu SPIP method. Piperine, isolated was found to be $99 \%$ pure and ginger resin contained $4.36 \% \mathrm{w} / \mathrm{w}$ of gingerol. The absorption of amoxicillin increased with addition of Piperine (1.2, $1.5,1.8 \% \mathrm{w} / \mathrm{w}$ of amoxicillin) in a dose dependant manner reaching saturation after 45 minutes wheras Ginger resin $(6,7,8 \% w / w$ of amoxicillin) failed to show this effect in the invitro studies. Piperine enhanced the permeation of Amoxicillin but ginger resin failed to show this effect using the insitu SPIP method. The method used may be appropriate for bioenhancers acting on transporters, metabolizing enzymes or modulators of diffusivity but not for those acting on gut motility. The combination of Piperine and Amoxicillin trihydarte may have a potential in reducing the dose, shortening the treatment period thus reducing drug-resistance problems of the antibiotic.
\end{abstract}

\section{Keywords}

Piperine; Gingerol; BCS Classification; Black pepper; Ginger; Ayurveda

\section{Introduction}

Three major factors namely solubility, dissolution, and intestinal permeability, affecting oral drug absorption can be estimated using the biopharmaceutics classification system (BCS). It classifies the drug into four classes: Class I (high solubility, high permeability), Class II (low solubility, high permeability), Class III (high solubility, low permeability) and Class IV (low solubility, low permeability).

Some of the very commonly used antibiotics fall into Class III and Class IV category according to this system. One such antibiotic is Amoxicillin which has a low permeability [1] and has been classified into Class III drugs [2]. Amoxicillin is absorbed by passive diffusion and via active transport through oligopeptide carrier localized at the apical enterocyte membrane (PePT1). The drug is reported to have low bioavailability in rats [3] as well as in humans [4]. In spite of being an effective antibiotic, it is losing importance in chemotherapy due to less bioavailability. The permeability of such low permeability drugs can be enhanced by co administration of bioenhancers. 
Bioenhancers are agents, which by themselves are not therapeutic entities but when combined with an active drug lead to the potentiation of the pharmacological effect of the drug. Such enhancers have been found to increase the bioavailability of a number of drugs at very low concentrations. In general, they can enhance the bioavailability by enhancing the passive diffusion or by inhibiting the efflux transporters [5] (PgP) and other multidrug resistance proteins (MRPs) [6]. Piperine and Ginger resin are known to be the constituents of trikatu, an Ayurvedic formulation, indicating three drugs which enhance the bioavailability [7]. In the present study the effect of Piperine and Ginger resin on the absorption of Amoxicillin has been studied using in vitro and in vivo models.

\section{Experimental}

Plant material: Black pepper and ginger was procured from the local market and subjected to extraction of the active constituents.

Chemicals: Amoxicillin trihydrate, Atenolol and Propranolol hydrochloride were obtained as gift samples from IPCA laboratories, Mumbai. Urethane was procured from Sigma Aldrich, India and other chemicals and solvents were of analytical grade and procured from commercial sources.

Isolation of piperine [8]: $300 \mathrm{~g}$ of black pepper powder was extracted with 1.5 liters of $95 \%$ ethanol in a Soxhlet extractor at $60-70{ }^{\circ} \mathrm{C}$. The solution was filtered and concentrated in vacuum on a water bath at $60{ }^{\circ} \mathrm{C}$. Alcoholic potassium hydroxide $(10 \% \mathrm{w} / \mathrm{v})$ was added to the filtrate residue and kept overnight in a refrigerator at $2-8{ }^{\circ} \mathrm{C}$. The yellow crystals of piperine were deposited at the bottom of the flask which were then washed and purified with organic solvents. Recrystallisation was done with acetone. Piperine crystals were stored for further use.

Analysis of isolated piperine: The isolated Piperine was subjected to HPLC analysis using Microsorb-MV 100-5 C18 column, Acetonitrile: $0.1 \%$ orthophosphoric acid (60:40) as mobile phase, UV -Visible detector at $340 \mathrm{~nm}$ at ambient temperature and a flow rate of $1 \mathrm{ml} / \mathrm{min}$.

Preparation of ginger resin: $500 \mathrm{~g}$ of ginger powder was extracted with $2 \mathrm{~L}$ of $95 \%$ ethanol in a Soxhlet extractor at $60-70{ }^{\circ} \mathrm{C}$. The extract was evaporated by distillation and collection of the excess filtered solvent was carried out. The extract was further concentrated on a rotary evaporator. Ginger resin was stored for further use.

Quantitative estimation of Ginger resin: Ginger resin sample was sent to Natural Remedies Pvt. Ltd. (Bangalore) for estimation of gingerol content by HPTLC.

In vitro studies using Franz diffusion cell: Amoxicillin solution $(10 \mathrm{mg} / \mathrm{ml})$ was added to the reservoirs with Phosphate Buffer Solution (PBS) pH 7.4 as the medium in the diffusion cell. Varying concentrations of Piperine $(1.2,1.5$ and $1.8 \% \mathrm{w} / \mathrm{w})$ [9] and Ginger resin $(6,7$ and $8 \% \mathrm{w} / \mathrm{w})[9,10]$ were added to different reservoirs to check the enhancement in diffusion across the synthetic semi permeable membrane.

Invitro studies using non everted gut sac method [3]: The pig intestine was procured from Deonar slaughter house, Mumbai, India. It was cleaned and sacs of about $3 \mathrm{~cm}$ in length were made from the ileum. The empty sac was filled with $1 \mathrm{ml}$ of amoxicillin $(6 \mathrm{mg} / \mathrm{ml})$ in PBS (pH 7.4) using a blunted syringe. The needle was then slipped off carefully, and the loose ligature on the proximal end was tightened. The serosal compartment contained buffer in the sac. The distended sac was placed inside organ tube of organ bath containing $50 \mathrm{ml}$ PBS. This gut sac bath was surrounded by a water jacket maintained at $37 \pm 0.5^{\circ} \mathrm{C}$. The mucosal fluid compartment content was continuously mixed with air bubbles using an aerator. At predetermined intervals, $5 \mathrm{ml}$ of sample was withdrawn from the organ tube and same volume was 
replaced with fresh buffer. The concentration of drug that traversed intestinal surface was monitored at $273 \mathrm{~nm}$ spectrophotometrically. Experiment was repeated with $1.5 \% \mathrm{w} / \mathrm{w}$ of Piperine and $8 \% \mathrm{w} / \mathrm{w}$ of ginger resin added to the sac.

In vivo studies using single pass intestinal perfusion method (SPIP) [11]: The intestinal transport of Amoxicillin trihydrate was investigated using SPIP technique. Male Wistar rats (200-250 g) were procured from Bharat Serum, Thane. Animals were acclimatized for a week before use in the SPIP study. All animal experiments were carried out in accordance with guidelines of CPCSEA and the study was approved by the Institutional Animal Ethical committee (CPCSEA/ IAEC/SPTM/P-20/2014). Rats were fasted for $12 \mathrm{~h}$ (water ad libitum) prior to each experiment. Anesthesia was induced with urethane $(1.25 \mathrm{gm} / \mathrm{kg}$, i.p.). The abdomen was opened with a midline incision and an intestinal segment of approximately $10 \mathrm{~cm}$ was measured, isolated and cannulated with plastic tubing. Initially, the intestinal segment was rinsed with isotonic saline until the outlet solution was clear. Amoxicillin solution $(100 \mu \mathrm{g} / \mathrm{ml})$ was given by a constant perfusion at flow rate of $0.2 \mathrm{ml} / \mathrm{min}$. Each perfusion experiment lasted for $60 \mathrm{~min}$ and the perfusate was quantitavely collected at 15, 30, 45 and 60 min marks. The collected samples were then analyzed by UV spectroscopy. Krebs-Ringer buffer solution was used as blank perfusion solution. Phenol red solution was added as non-absorbable biomarker to calculate net water flux. Propranolol hydrochloride and Atenolol were used as high permeability and low permeability markers to validate the procedure. Experiment was repeated with $1.5 \% \mathrm{w} / \mathrm{w}$ of piperine and $8 \% \mathrm{w} / \mathrm{w}$ of ginger resin added to the perfusate. Effective permeability values were calculated from the steady-state concentrations of Amoxicillin trihydrate in the perfusate collected from the outlet. In vivo drug intestinal permeability in humans $\left(P_{\text {eff,man }}\right)$ can be predicted from rat $P_{\text {eff }}$ values according to following formula [12]:

$$
P_{\text {eff }} \text { man }=3.6 * P_{\text {eff }, \text { rat }}+0.03 * 10^{-4} \text {. }
$$

\section{Results and Discussion}

In vitro studies using Franz diffusion cell

As shown in Table 1, there was a dose dependant and time dependant increase in the diffusion of Amoxicillin trihydrate on addition of Piperine. Piperine at a concentration of $1.2 \% \mathrm{w} / \mathrm{w}$ did not show a significant increase at 15 and $30 \mathrm{~min}$ but the diffusion increased significantly at 45 and 60 minutes. Piperine concentrations of 1.5 and $1.8 \% \mathrm{w} / \mathrm{w}$ significantly enhanced the diffusion of Amoxicillin trihydrate at 15, 45 and $60 \mathrm{~min}(\mathrm{p}<0.0001)$. However 1.5 and $1.8 \% \mathrm{w} / \mathrm{w}$ of Piperine additions did not show a significant difference in the diffusion of Amoxicillin trihydrate when compared with each other. Hence $1.5 \% \mathrm{w} / \mathrm{w}$ of Piperine was selected for the rest of the studies.

Use of ginger resin with Amoxcillin trihydrate failed to show a dose dependant increase in the diffusion. 6 and $8 \% \mathrm{w} / \mathrm{w}$ of ginger resin demonstrated a significant increase $(p<0.0001)$ in the diffusion which was also dose and time dependant. However $7 \% \mathrm{w} / \mathrm{w}$ of ginger resin failed to show such increase till $45 \mathrm{~min}$, but a significant increase $(p<0.0001)$ was observed at $60 \mathrm{~min}$. Hence, we selected $8 \% \mathrm{w} / \mathrm{w}$ of ginger resin for the rest of the experiments.

\section{In vitro studies using non everted gut sac method}

The results for this study are shown in Table 2. $1.5 \% \mathrm{w} / \mathrm{w}$ Piperine showed a significant increase $(p<0.0001)$ in the permeation at all time, however after 45 minutes it reached a plateau and did not show 
any significant increase in the permeation. $8 \% \mathrm{w} / \mathrm{w}$ of ginger resin demonstrated a significant reduction in the permeation of amoxicillin trihydrate.

Table 1. Cumulative concentration of Amoxicillin trihydrate using semi permeable membrane

\begin{tabular}{|c|c|c|c|c|c|c|c|}
\hline \multirow[t]{2}{*}{ Time } & \multirow{2}{*}{$\begin{array}{c}\text { Amoxicillin } \\
(\mu \mathrm{g} / \mathrm{ml})\end{array}$} & \multicolumn{3}{|c|}{$\begin{array}{c}\text { Amoxcillin + Piperine } \\
(\mu \mathrm{g} / \mathrm{ml}) \\
\end{array}$} & \multicolumn{3}{|c|}{$\begin{array}{c}\text { Amoxcillin + Ginger resin } \\
(\mu \mathrm{g} / \mathrm{ml})\end{array}$} \\
\hline & & $1.2 \% \mathrm{w} / \mathrm{w}$ & $1.5 \% \mathrm{w} / \mathrm{w}$ & $1.8 \% w / w$ & $6 \% w / w$ & $7 \% w / w$ & $8 \% w / w$ \\
\hline $15 \mathrm{~min}$ & $6.79 \pm 0.06$ & $6.05 \pm 0.21$ & $8.34 \pm 0.07^{* * *}$ & $9.89 \pm 0.09 * * *$ & $7.12 \pm 0.10^{* * *}$ & $4.4 \pm 0.050$ & $8.82 \pm 0.14^{* * *}$ \\
\hline $30 \min$ & $9.91 \pm 0.08$ & $8.83 \pm 0.11$ & $10.06 \pm 0.12$ & $12.28 \pm 0.06 *$ & $12.28 \pm 0.06$ & $5.55 \pm 0.08$ & $27.04 \pm 2.86 * * *$ \\
\hline $45 \min$ & $10.07 \pm 0.08$ & $18.14 \pm 0.54^{* * *}$ & $29.14 \pm 0.25^{* * *}$ & $32.18 \pm 0.63 * * *$ & $15.75 \pm 0.18 * * *$ & $10.37 \pm 0.11$ & $32.76 \pm 0.18^{* * *}$ \\
\hline $60 \mathrm{~min}$ & $14.53 \pm 0.14$ & $26.35 \pm 0.2^{* * *}$ & $54.59 \pm 0.18 * * *$ & $54.91 \pm 4.30 * * *$ & $23.38 \pm 0.09 * *$ & $26.55 \pm 0.12 * * *$ & $42.87 \pm 4.17^{* * *}$ \\
\hline
\end{tabular}

$\mathrm{n}=6$, values are written as mean $\pm \mathrm{SD},{ }^{* * *} \mathrm{p}<0.0001,{ }^{* *} \mathrm{p}<.001,{ }^{*} \mathrm{p}<0.01$ when compared to Amoxicillin trihydrate using one way ANOVA followed by Bonferroni multiple comparison.

Table 2. Cumulative concentration of Amoxicillin trihydrate using non everted gut sac

\begin{tabular}{|c|c|c|c|}
\hline \multirow{2}{*}{ Time } & \multirow{2}{*}{ Amoxicillin $(\mu \mathrm{g} / \mathrm{ml})$} & Amoxcillin + Piperine $(\mu \mathrm{g} / \mathrm{ml})$ & $\begin{array}{c}\text { Amoxcillin + Ginger resin } \\
(\mu \mathrm{g} / \mathrm{ml})\end{array}$ \\
\cline { 3 - 4 } & & $1.5 \% \mathrm{w} / \mathrm{w}$ & $8 \% \mathrm{w} / \mathrm{w}$ \\
\hline $15 \mathrm{~min}$ & $15.76 \pm 0.14$ & $38.33 \pm 0.07^{* * *}$ & $7.44 \pm 0.05^{* * *}$ \\
\hline $30 \mathrm{~min}$ & $27.96 \pm 0.07$ & $41.51 \pm 0.14^{* * *}$ & $15.9 \pm 0.08^{* * *}$ \\
\hline $45 \mathrm{~min}$ & $35.64 \pm 0.07$ & $43.41 \pm 0.08^{* * *}$ & $20.17 \pm 0.12^{* * *}$ \\
\hline $60 \mathrm{~min}$ & $50.02 \pm 0.31$ & $44.85 \pm 0.08$ & $23.51 \pm 0.08^{* * *}$ \\
\hline
\end{tabular}

$\mathrm{n}=6$, values are written as mean $\pm S D, * * * p<0.0001$ when compared to Amoxicillin trihydrate using one way ANOVA followed by Bonferroni multiple comparison

\section{In vivo studies using single pass intestinal perfusion method (SPIP)}

Table 3 shows the effective permeability in rats and humans. The $P_{\text {eff }}$ of Atenolol was found to be $0.106 \pm 0.012 \times 10^{-4}$ and $0.4116 \pm 0.041 \times 10^{-4}$ in rats and humans respectively which is in compliance with the reported values 12 . Similarly the $P_{\text {eff }}$ of Propranolol hydrochloride was found to be $1.14 \pm 0.082 \times 10^{-4}$ and $4.134 \pm 0.236 \times 10^{-4}$ in rats and humans respectively, which again complies with the reported values for effective permeability [13]. This indicates the validity of the SPIP method.

For SPIP techniques drugs with $P_{\text {eff,Rats }}>0.2 \times 10^{-4} \mathrm{~cm} / \mathrm{sec}$ and $P_{\text {eff,Man }}>0.7 \times 10^{-4} \mathrm{~cm} / \mathrm{sec}$ can be considered as highly permeable $[14,15]$. The $P_{\text {eff }}$ of Amoxicillin trihydrate in rats and humans was found to be $0.16 \times 10^{-4} \mathrm{~cm} /$ in rat and $0.617 \times 10^{-4} \mathrm{~cm} / \mathrm{s}$ respectively, thus it can be classified as poorly absorbed drug. $1.5 \% \mathrm{w} / \mathrm{w}$ of piperine increased the permeation by $60 \%$ and $54.13 \%$ in rats and humans respectively ( $p<0.001) .8 \% \mathrm{w} / \mathrm{w}$ of ginger resin did not show any significant change in the $P_{\text {eff }}$ of Amoxicillin trihydrate showing no bioenhancement. 
Table 3. Effective permeability values of Atenolol, Propranolol hydrochloride and Amoxicillin trihydrate

\begin{tabular}{|c|c|c|c|c|c|}
\hline & Atenolol & Propranolol & Amoxicillin & $\begin{array}{c}\text { Amoxicillin + } \\
\text { Piperine (1.5\% } \\
\mathbf{w} / \mathbf{w})\end{array}$ & $\begin{array}{c}\text { Amoxicillin + } \\
\text { Ginger (8 \% w/w) }\end{array}$ \\
\hline $\begin{array}{c}P_{\text {eff }} \text { in rats } \\
(\mathrm{cm} / \mathrm{s})\end{array}$ & $0.106 \pm 0.012 \times 10^{-4}$ & $1.140 \pm 0.082 \times 10^{-4}$ & $0.16 \pm 0.03 \times 10^{-4}$ & $0.256 \pm 0.021 * * \times 10^{-4}$ & $0.19 \pm 0.025 \times 10^{-4}$ \\
\hline $\begin{array}{c}P_{\text {eff }} \text { in } \\
\text { humans } \\
(\mathrm{cm} / \mathrm{s})\end{array}$ & $0.412 \pm 0.041 \times 10^{-4}$ & $4.134 \pm 0.236 \times 10^{-4}$ & $0.618 \pm 0.056 \times 10^{-4}$ & $0.9516 \pm 0.08^{* *} \times 10^{-4}$ & $0.714 \pm 0.068 \times 10^{-4}$ \\
\hline
\end{tabular}

$\mathrm{n}=6$, values are written as mean $\pm S D,{ }^{* *} \mathrm{p}<0.001$ when compared to Amoxicillin trihydrate using one way ANOVA followed by Dunnetts multiple comparison

We have tried to evaluate enhancement of bioavailability using the in situ SPIP method. The in situ SPIP technique not only preserves the microclimatic conditions of the intestine but also counts the transporter activity in the same experimental condition. The result obtained with Piperine confirms the use of this method for such type of study. Amoxicillin trihydrate is absorbed from the intestine via passive diffusion and active transport using the PEPT1 transporters but at the same time is also a substrate to an energy demanding efflux system distinct from the P-glycoprotein mediated transport system which may contribute to restricted intestinal absorption [4]. Piperine is known to induce alterations in membrane dynamics and permeation characteristics and thereby increase the passive diffusion of Amoxicillin trihydrate $[16,17]$. Piperine is also reported to be inhibitor of drug efflux pump one of them being PgP efflux transporter [18], thereby reducing the efflux and enhancing the availability of Amoxicillin trihydrate. Piperine at the same time inhibits a number of enzymes involved in metabolism of drugs and nutrients, thus reducing the metabolism of drugs and prolonging the drug effect [19]. Moreover it is also known to reduce the rate of glucuronidation permitting the entry of active drug substance [19]. Ginger is known to enhance the bioavailability by regulating the GIT function [20]. Although there are reports which indicate that use of ginger extract enhances the bioavailability of many drugs [21-23], we did not get satisfactory results, which is suggestive that bioenhancers working on the gut motility may not be the right candidates to be studied by this method. It may also be possible that the ginger extract might be forming a coating over the mucosal surface thereby hindering the absorption of Amoxicillin trihydrate. Ginger is reported to have prokinetic property $[24,25]$, thus it increases the intestinal motility, due to this the drug remains in contact with the mucosal surface for lesser time and hence may not be absorbed to the expected significance.

\section{Conclusions}

The results demonstrate that Piperine can be effectively used in combination with Amoxicillin trihydrate to increase the biovaialbility of the later, however ginger resin did not give anticipated results of bioenhancement. The combination with piperine may help in reducing the dose, shortening the treatment period thus reducing drug-resistance problems. The treatment may be made cost effective, minimizing drug toxicity and adverse reactions. In future, formulation may be developed by combining Piperine with Amoxicillin trihydrate.

Such nature derived bioenhancers may be used in combination with other drug classes like, antitubercular, antiviral, antifungal and anticancer drugs to enhance the bioavailability. Oral absorption of vitamins, minerals, herbal extracts, amino acids and other nutrients can also be enhanced. 
Acknowledgements: The authors are grateful to SPP-School of Pharmacy and Technology Management, SVKM's NMIMS for funding this project. The authors would also like to acknowledge IPCA laboratories, Mumbai, India for providing gift samples.

\section{References}

[1] H. Lennernasa, L. Knutsonb, T. Knutsonb, A. Hussainc , L. Leskoc , T. Salmonsond, European Journal of Pharmaceutical Sciences 15 (2002) 271-277.

[2] W. Chi-Yuan, Z.B. Leslie, Pharm. Res. 22 (2005) 11-23.

[3] B. Ali, S. Amin, J. Ahmad, A. Ali, M. Ali ,S. R. Mir, Indian J. Med. Res. 135 ( 2012 ) 555-559.

[4] I. Legen, M. Kra cun, M. Salobir, J. Kerc, International Journal of Pharmaceutics 308 (2006) 84-89.

[5] B.J. Aungst, J. Pharm. Sci. 89 (2000) 429-442.

[6] K. Bogman, F. Erne-Brand, J. Alsenz, J. Drewe, J. Pharm. Sci. 92 (2003) 1250-1261.

[7] W.C. Evans, Trease and Evans Pharmacognosy, Elsevier Limited, China, 2009, p. 56.

[8] R. Ikan, Natural Products A laboratory guide, Academic Press, New Delhi, India, 2005, p.233-235.

[9] www.hindawi.com, http://dx.doi.org/10.1100/2012/637953 (27/01/2015).

[10] C.V. Jacob,(Synthite Industries Ltd) US20120058208A1 (2012).

[11] J.R. Patel, K.H. Barve, Indian Journal of Pharmaceutical Sciences 74 (2012) 478-481.

[12] U. Fagerholm, M. Johansson, H. Lennernas, Pharmaceutical Research 13 (1996) 1336-1342.

[13] H. Lennernas, L. Knustson, R. Knutson, L. Lesko, T. Salmonson, G.L. Amidon, Eur. J. Pharm. Sci. 4 (1996) S69.

[14] D.A. Volpe, H. Moller, L.X. Yu, In: Lehr CM (ed.) Cell Culture Models of Biological Barriers: In Vitro Test Systems for Drug Absorption and Delivery. London, New York. Taylor \& Francis Publishing Group, 130-139.

[15] P.Z. Milani, H. Valizadeh, H. Tajerzadeh, Y. Azarmi, Z. Islambolchilar, S. Barxegar, M. Jalai, J. Pharm. Pharmaceut. Sci. 10 (2007) 368-379.

[16] S. Bajad, K.S. Bedi, A.K. Singla, R.K. Johri, Planta Med. 67 ( 2001) 176-179.

[17] S. Wadhwa, S. Singhal, S. Rawat, Asian Journal of Biomedical and Pharmaceutical Sciences 4 (2014) 1-8.

[18] U.K. Patil, A. Singh, A.K. Chakraborty, International Journal of Recent Advances in Pharmaceutical Research 4 (2011) 16-23.

[19] P. Gohil , A. Mehta, Oriental Pharmacy and Experimental Medicine 9 (2009) 269-276.

[20] D.V. Tatiraju, V.B. Bagade, P.J. Karambelkar, V.M. Jadhav, V. Kadam, Journal of Pharmacognosy and Phytochemistry 2(2013)55-60.

[21] S. O. Nduka, E.O. Okonta, L.Z. Adonu, J.M. Okonta, International Journal of Applied Research in Natural Products 6 (2013) 15-18.

[22] B. Jhanwar, S. Gupta, International Journal of PharmTech Research 6 (2014) 443-454.

[23] N. Atal , K.L. Bedi, J. Ayurveda Integr. Med. 1 (2010) 96-99.

[24] M.N. Ghayur , A.H. Gilani, Digestive Diseases and Sciences 50 (2005) 1889-1897.

[25] A.M. Bode, Z. Dong, in Herbal Medicine: Biomolecular and Clinical Aspects. Eds: I.F.F. Benzie, S. Wachtel-Galor, 2nd edition., CRC Press, Boca Raton, Florida, United States of America 2011.

C2015 by the authors; licensee IAPC, Zagreb, Croatia. This article is an open-access article distributed under the terms and conditions of the Creative Commons Attribution license (http://creativecommons.org/licenses/by/3.0/) (cc)) EY 